\title{
PATRIMONIALIZAÇÃO DO SISTEMA AGRÍCOLA TRADICIONAL QUILOMBOLA DO VALE DO RIBEIRA-SP ${ }^{1}$
}

\section{PATRIMONIALIZATION OF THE QUILOMBOLA'S TRADITIONAL AGRICULTURAL SYSTEM AT VALE DO RIBEIRA-SP}

\section{PATRIMONIALIZACIÓN DEL SISTEMA AGRÍCOLA TRADICIONAL QUILOMBOLA DEL VALE DO RIBEIRA-SP}

\author{
Denise Martins de Sousa ${ }^{2}$ https://orcid.org/0000-0002-0516-8836
}

\footnotetext{
${ }^{1}$ Este artigo é parte da pesquisa de doutorado em andamento no Programa de Pós-Graduação em Geografia Humana- FFLCH/USP.

${ }^{2}$ Graduada em Geografia (Licenciatura e Bacharelado), Mestra e Doutoranda em Geografia Humana pela Universidade de São Paulo

- USP, Bolsista CAPES. E-mail: denise.sousa@usp.br
}

\section{RESUMO}

Este artigo tem por objetivo discutir e analisar o processo de reconhecimento do Sistema Agrícola Tradicional (SAT) das Comunidades Quilombolas do Vale do Ribeira como patrimônio cultural imaterial brasileiro e os seus desdobramentos atuais. O estudo parte do reconhecimento do SAT em questão, enquanto patrimônio da cultura imaterial, e como isso afeta diretamente o modo de vida dessas comunidades quilombolas. A pesquisa pautou-se no Dossiê elaborado pelo Instituto Socioambiental (Isa) na construção de referências para o reconhecimento do SAT quilombola, material esse que tem por base metodológica o Inventário Nacional de Referências Culturais (INRC) para o Registro de Bens Culturais de Natureza Imaterial, elaborado pelo Instituto do Patrimônio Histórico e Artístico Nacional (Iphan), além de autores que trabalham com o campo do patrimônio, cultura, memória e comunidades quilombolas. Tal debate acerca da patrimonialização das roças tradicionais se coloca como fundamental, ao aprofundar a discussão sobre o tema, assim como, para a visibilidade e salvaguarda dos bens da cultura imaterial das populações subalternas como indígenas e negros, ao mesmo tempo que potencializa ações para resistir a pressões e ao risco de desaparecimento de suas culturas e suas práticas sociais relacionadas no cotidiano à natureza.

Palavras-chave: Patrimônio Cultural Imaterial. Quilombos. Sistema Agrícola Tradicional.

\begin{abstract}
This article aims to discuss and analyze the recognition process of the Quilombola's Traditional Agricultural System (TAS) at Vale do Ribeira as a Brazilian Intangible Cultural Heritage, as well as its developments. The study starts from the recognition of the TAS as intangible cultural heritage, and how it directly affects the way of life of these communities. The research traces the methodological path of analysis of the dossier prepared by the Socio-environmental Institute (ISA) in the construction of references for the recognition of the TAS quilombola, material that is based on the National
\end{abstract}


Inventory of Cultural References (INRC) for the Register of Cultural Assets of Intangible Nature, prepared by the Institute of National and Artistic Heritage (Iphan), as well as authors who work with the field of heritage, culture, memory, and quilombos. Such debate about the patrimonialization of traditional farming presents itself as fundamental, as it deepens the discussion on the theme, and gives visibility and safeguarding for the subaltern population's immaterial culture assets, such as indigenous and black people. At the same time, it enhances actions to resist the pressures and the risk of the disappearance of their cultures and their social practices related, in their daily lives, to nature.

Keywords: Intangible Cultural Heritage. Quilombos. Traditional Agricultural System.

\section{RESUMEN}

Este artículo tiene como objetivo discutir y analizar el proceso de reconocimiento del Sistema Agrícola Tradicional (SAT) de las comunidades Quilombolas del Vale do Ribeira como patrimonio cultural inmaterial brasilero y de su desarrollo actual. E estudio parte del reconocimiento del SAT como patrimonio de la cultura inmaterial, y como eso afecta directamente el modo de vida de estas comunidades. La investigación traza el camino metodológico de análisis de dosier elaborado por el Instituto Socioambiental (ISA) en la construcción de referencias para el reconocimiento del SAT quilombola, material que tiene como base el Inventario Nacional de Referencias Culturales (INRC) para el Registro de Bienes Culturales de Naturaleza Inmaterial, elaborado por el Instituto de Patrimonio Histórico y Artístico Nacional (Iphan), así como autores que trabajan en el campo de patrimonio, cultura, memoria y quilombos. Tal debate acerca de la patrimonialización de los campos tradicionales se coloca como fundamental, al profundizar en la discusión sobre el tema, así como, para la visibilidad y salvaguarda de los bienes de la cultura inmaterial de las poblaciones subalternas como indígenas y negros, al mesmo tiempo que potencializa acciones para resistir a las presiones y al riesgo de desaparición de sus culturas e de sus prácticas sociales relacionadas en lo cotidiano a la naturaleza.

Palabras clave: Patrimonio Cultural Inmaterial. Quilombos. Sistema Agrícola Tradicional.

\section{INTRODUÇÃO}

O espaço agrário brasileiro é permeado por realidades diversas e contraditórias dentro da lógica de uma sociedade capitalista. No contexto de diversidade existente no campo, destaca-se, atualmente, uma proposta das comunidades remanescentes de quilombos ${ }^{3}$ do Vale do Ribeira paulista de reconhecimento de seus saberes e práticas relacionadas às roças tradicionais.

\footnotetext{
${ }^{3} \mathrm{O}$ termo "remanescentes de quilombo" obteve um amplo debate acadêmico, jurídico e técnico a partir da promulgação da Constituição de 1988. Logo, houve a necessidade de regulação do artigo 68 do Ato das Disposições Transitórias da Constituição Federal de 1988, que assegura a propriedade definitiva das terras às comunidades remanescentes de quilombos sob o enunciado: "Aos remanescentes das comunidades de quilombos que estejam ocupando suas terras é reconhecida a propriedade definitiva, devendo o Estado, emitir-lhes os respectivos títulos" (BRASIL, 2016, p.160). Os grupos que hoje são identificados como remanescentes de quilombos se constituem a partir de uma grande diversidade de processos que incluem as fugas, heranças, doações de terras, recebimento de terras como pagamento de serviços prestados ao Estado, simples permanência nas terras que ocupavam e cultivaram no interior das grandes propriedades, bem como a compra de terras, tanto durante a vigência do sistema escravocrata quanto após a sua extinção (ARRUTI, 1999; destaque nosso).
} 
Em setembro de 2018, por uma decisão unanime do Conselho Consultivo do Patrimônio Cultural do Instituto do Patrimônio Histórico e Artístico Nacional (Iphan), a agricultura quilombola tradicional do Vale do Ribeira é reconhecida como Patrimônio Cultural Imaterial Brasileiro, denominado como Sistema Agrícola Tradicional (SAT) das comunidades quilombolas do Vale do Ribeira.

O pedido para o reconhecimento do SAT quilombola do Vale do Ribeira como patrimônio cultural brasileiro foi manifestado pelos próprios sujeitos sociais, por meio da articulação e assessoria dos profissionais que atuam no Instituto Socioambiental (Isa) e amparado na metodologia do Iphan ${ }^{4}$. Este esforço de solicitar o registro foi pensado ao longo de alguns anos de trabalhos junto às comunidades quilombolas. Dentre os trabalhos em parceria com os quilombos e essa Ong, em 2008, temos a elaboração de um projeto que resultou na "Agenda socioambiental de comunidades quilombolas do Vale do Ribeira". Alguns anos mais tarde, ocorre a publicação do "Inventário Cultural de Quilombos do Vale do Ribeira" no qual as comunidades identificaram o bem cultural "modo de fazer roça" como relevante ao modo de vida, entre outros ofícios e modos de fazer (ANDRADE; TATTO, 2013).

No Brasil, o debate e as políticas de patrimônio cultural, que remontam à década de 1930, tomam novo relevo nas décadas de 1970 e 1980, com o surgimento de demandas sociais, ambientais, artísticas, entre outras que representam a sociedade civil e que passam a integrar as políticas culturais. Esse período é de uma revisão crítica da noção de patrimônio cultural (PEREIRA, 2018).

Meneses (2012) revela que, o debate que permeava no Iphan era a premissa de preservação do patrimônio enquanto fator social e não como obra excepcional. Esta afirmação causou estranheza no campo da preservação patrimonial. E consolida-se uma "prática esquizofrênica" com as novas diretrizes constitucionais ${ }^{5}$. Como diria o autor, a atuação no

\footnotetext{
${ }^{4} \mathrm{O}$ pedido e a efetivação do registro do SAT, solicitado pelas comunidades quilombola do Vale do Ribeira, obteve a mediação e o trabalho de assessoria técnica dos profissionais que atuam no Instituto Socioambiental (Isa). Foi utilizado a metodologia do Inventário Nacional de Referências Culturais (INRC), de autoria do Iphan e desenvolvido pelo Departamento de Patrimônio Imaterial - DPI, resultando no dossiê que foi entregue para o registro desse bem imaterial.
}

${ }^{5}$ Nos artigos 215 e 216, a Constituição reconhece a existência de bens culturais de natureza material e imaterial, além de estabelecer as formas de preservação desse patrimônio: o registro, o inventário e o tombamento. Temos que as diretrizes constitucionais referentes ao patrimônio não são mais pautadas no que os órgãos públicos determinam, mas no que as comunidades reconhecem por valor cultural: "o poder público, com a colaboração da comunidade, promoverá e protegerá o patrimônio cultural brasileiro, por meio de inventários, registros, 
campo do patrimônio cultural, necessita de clareza e de defrontar-se, inicialmente, "com a problemática do valor, que ecoa em qualquer esfera do campo". Trabalhar com o campo do valor é estar diante de uma "arena de conflitos" (MENESES, 2012, p.32).

No entendimento do campo da cultura e, em consequência, o do patrimônio cultural, deve levar-se em conta "a sua marca eminentemente política, ou seja, é gerido e compartilhado pelos cidadãos" (MENESES, 2012, p.38). Atuar com o tema do patrimônio cultural é ter postura crítica que a complexidade do campo exige. Como recorda Smith (2011), o patrimônio é um ato comunicativo.

A partir da Constituição Federal de 1988, ocorre a introdução de novas categorias de patrimônio cultural, dentre essas inclui-se o patrimônio intangível. As "formas de expressão, modos de criar e fazer viver" estão entre as categorias, o que inclui o "saber-fazer". O patrimônio cultural se alicerça em "vetores materiais", e o mesmo ocorre com o patrimônio imaterial, já que "todo patrimônio material tem uma dimensão imaterial de significado e valor, por sua vez todo patrimônio imaterial tem uma dimensão material que lhe permite realizar-se" (MENESES, 2012, p.34).

Meneses (2009) recorda-nos que existe uma dimensão existencial do patrimônio: a memória. A memória é parte do vivido. Podemos seguir nessa reflexão, a partir do debate de Nora (1993), que a memória se torna um instrumento ou uma estratégia política que permite a coesão ao grupo social que reivindica o reconhecimento de seus saberes e práticas como patrimônio pelo Estado, do mesmo modo que ela constitui como um processo de resistência contra o esquecimento.

Muitos dos aspectos da agricultura tradicional quilombola podem ser avaliados por meio da reconstrução das rememorações ${ }^{6}$ das narrativas orais dos moradores que vivenciaram os antigos modos de se relacionar com a natureza e que, consequentemente, são as bases para o desenvolvimento de toda uma forma particular de sociabilidade, reciprocidade e práticas culturais que os legitimam enquanto quilombolas. Os grupos subalternos podem e devem chamar para si o protagonismo da proteção de suas memórias, assim como, lutar pela

vigilância, tombamento e desapropriação, e de outras formas de acautelamento e preservação" (BRASIL, 1988, art. $\left.216, \S 1^{\circ}\right)$.

${ }^{6} \mathrm{O}$ conceito de rememoração foi abordado pelo pensador alemão Walter Benjamin, para quem a rememoração “[...] funda a cadeia da tradição, que transmite os acontecimentos de geração em geração. Ela corresponde à musa épica no sentido mais amplo. Ela inclui todas as variedades da forma épica. Entre elas, encontra-se em primeiro lugar a encarnada pelo narrador. Ele tece a rede que em última instância todas as histórias constituem entre si [...]" (BENJAMIN, 2012, p. 228). 
preservação de seu patrimônio cultural, no caso das comunidades quilombolas do Vale do Ribeira, o imaterial.

Quanto à política de patrimônio imaterial ${ }^{7}$ adotada pelo Iphan, a partir de 2000, essa passou a desenvolver uma visão de reconhecimento do campo da cultura como "totalidade da vida social, enquanto diferencialmente qualificada (pelos sentidos, valores)". As "linhas de ação, como 'sistemas agrícolas tradicionais', por exemplo, são capazes de articular organicamente facetas à primeira vista tão alheias à cultura, quando ela é equivocadamente entendida como uma gaveta à parte" (MENESES, 2009, p.29),

A agricultura tradicional quilombola corresponde a experiências adquiridas e acumuladas na vivência, pesquisa e observação das dinâmicas da natureza ligadas aos resultados de manejos das comunidades. Esse etnoconhecimento compõe um repertório de saberes resultantes do passado, das origens africanas e indígenas. O $\operatorname{Iphan}^{8}$, no ano de 2018, considerou que o saber existente na roça tradicional quilombola é transmitido por meio de gerações e por via da oralidade e observação, em vivências práticas, considerando a formação do saber-fazer com o manejo dos recursos naturais para a agricultura. A esse saber-fazer também está o ato de ensinar, promover trocas, sentir e criar, tudo em total conexão à cultura popular da realização das roças tradicionais quilombolas (ANDRADE e KISHIMOTO, 2017).

A cultura popular "nasce da condição colonial, abaixo do limiar da escrita", como diria Bosi (1992) em Dialética da Colonização. Portanto, temos que ela é uma cultura da oralidade. O modo de fazer, de criar e as formas de expressões estão ligados à cultura popular. Se partimos de uma análise da cultura erudita, dominante, veremos que esta desconsidera, por completo, que a colonização provocou uma violência física para com os povos originários e os trazidos compulsoriamente pelo tráfico negreiro, do mesmo modo que promoveu uma violência simbólica, como um projeto de colonialidade do saber, uma colonialidade do poder.

\footnotetext{
${ }^{7} \mathrm{O}$ Iphan atendendo às determinações legais para criar instrumentos adequados ao reconhecimento e à preservação desses bens imateriais, coordenou os estudos que resultaram na edição do Decreto $n^{\circ}$. 3.551, de 4 de agosto de 2000 - que instituiu o Registro de Bens Culturais de Natureza Imaterial. Disponível em: http://portal.iphan.gov.br/uploads/ckfinder/arquivos/Decreto\%20n\%C2\%BA\%203 551\%20de\%2004\%20de\%20 agosto\%20de\%202000.pdf. Acesso em 20 nov 2020.

${ }^{8}$ Para saber mais: Parecer do Conselho Consultivo do Patrimônio Cultural - IPHAN reconhece o Sistema Agrícola Tradicional Quilombola como Patrimônio Cultural Brasileiro disponível em: <http://portal.iphan.gov.br/uploads/ckfinder/arquivos/PARECER__MANOELA_C_DA_CUNHA__DOC.pd f $>$ e $<$ http://portal.iphan.gov.br/noticias/detalhes/4838/sistema-agricola-tradicional-do-vale-do-ribeira-agora-epatrimonio-cultural-do-brasil>.
} 
A cultura, como coloca Bosi (1992, p.16), “é o conjunto das práticas, técnicas, símbolos e valores que se devem transmitir às novas gerações para garantir a reprodução de um estado de coexistência social". Partindo dessa premissa, Chauí (2014), em Conformismo e Resistência -, destacara que cultura popular é considerada uma "manifestação diferenciada que se realiza no interior de uma sociedade que é a mesma para todos, mas dotada de sentidos e finalidades diferentes para cada uma das classes sociais", e vai além:

[...] não trataremos a cultura popular, no Brasil, pelo prisma de uma totalidade que se opõe como antagônica à totalidade dominante, mas como um conjunto disperso de práticas, representações e formas de consciência que possui lógica própria (o jogo interno do conformismo, do inconformismo e da resistência), distinguindo-se da cultura dominante exatamente por essa lógica de práticas, representações e formas de consciência (CHAUÍ, 2014, p.27).

A cultura popular de que tratamos é a do oprimido, do dominado, do explorado e do subalterno, e que incorpora categorias para além da sociedade industrial. E, para compreendêla é importante ter empatia e colocar a centralidade do discurso nesses sujeitos sociais, pois, assim, demonstraremos que houve violência no processo da colonização.

Após as mudanças no processo que o patrimônio cultural passou com a Constituição de 1988, alguns anos mais tarde, em 1997, ocorre um retrocesso político que afetou as políticas de patrimônio, entre as quais a que se refere à cultura imaterial. Assim, "a política de patrimônio imaterial não pode ser lida apenas como uma renovação, pois ela é fragmentária e fruto de um momento de retrocesso político no país" (Informação verbal) ${ }^{9}$.

Segundo Carneiro da Cunha (2005), o patrimônio cultural imaterial se compõe muito mais de processos, do que de produtos e possui uma lógica própria, não consistindo em forma rigída e fixa; pelo contrário, ele depende do sentimento de continuidade e pertencimento a um território ancestral, de respeito aos saberes adquiridos dos antepassados, assim como, experiências e práticas acumuladas pelo grupo social. Como revela a antropóloga, atualmente compreende-se que o patrimônio cultural imaterial:

[...] se compõe de processos tanto, e provavelmente mais, do que de produtos; que ele não se compõe de formas fixas, mas de uma recriação permanente que tem a ver com um sentimento de continuidade em relação às gerações anteriores, ou seja, que ele é ao mesmo tempo dinâmico e histórico;

\footnotetext{
${ }^{9}$ Fala da Profa. Dra. Simone Scifoni na disciplina "Patrimônio cultural e projetos educativos" out. 2020 modalidade online (Virtual). Departamento de Geografia da Faculdade de Filosofia, Letras e Ciências Humanas - DG/FFLCH/USP.
} 
que suas condições de reprodução dependem, entre outras coisas, de acesso a território e a recursos naturais (CARNEIRO DA CUNHA, 2005, p. 13).

No caso quilombola, o patrimônio imaterial está intrínseco ao território ancestral como local de luta, de resistência, de reprodução da vida e de relação com a natureza.

\section{SAT QUILOMBOLA DO VALE DO RIBEIRA: RECONHECIMENTO COMO PATRIMÔNIO CULTURAL E SEUS DESDOBRAMENTOS}

O Estado de São Paulo apresenta em torno de 54 comunidades remanescentes de quilombos, das quais 36 foram regularizadas e reconhecidas pelo Instituto Nacional de Colonização e Reforma Agrária (Incra) e pela Fundação Instituto de Terras do Estado de São Paulo (Itesp) ${ }^{10}$. A maior parte dos territórios quilombolas em São Paulo estão localizados no Vale do Ribeira. Das comunidades remanescentes de quilombos apontadas, 27 foram reconhecidas e certificadas, somente 6 foram tituladas ou parcialmente tituladas em terras públicas devolutas ${ }^{11}$. No que concerne à relação entre quilombolas e as políticas públicas no país, não é raro ela ser pouco expressiva.

Entre avanços e retrocessos, quando se trata da política de reconhecimento de patrimônio imaterial, surge a proposta advinda das comunidades quilombolas do Vale do Ribeira de reconhecimento das suas roças tradicionais, denominada de Sistema Agrícola Tradicional (SAT), como patrimônio cultural brasileiro.

O primeiro SAT reconhecido e registrado como patrimônio cultural imaterial no país foi o Sistema Agrícola Tradicional do Rio Negro. A proposta de patrimonialização desse SAT serviu de base para a mobilização dos quilombolas do Vale do Ribeira, como revela Nilto Tatto em entrevista concedida à Ribeiro (2019):

[...] o registro do Sistema Agrícola Tradicional do Rio Negro como patrimônio imaterial serviu de inspiração para a mobilização dos quilombos do Vale do Ribeira que, ao levantarem os seus referenciais culturais, encaminharam o pedido de registro do Sistema Agrícola Tradicional de Comunidades Quilombolas do Vale do Ribeira. Baseando-se na metodologia do INRC e com o apoio técnico do IPHAN, 16 quilombos do vale e o Instituto Socioambiental (ISA) iniciaram em 2007 os trabalhos que culminaram na publicação do Inventário Cultural de Quilombos do Vale do Ribeira (2013), na apresentação do dossiê de registro (2014) e finalmente, o

\footnotetext{
10 No Estado de São Paulo, a regularização dessas áreas é também de competência do Itesp, vinculada à Secretaria da Justiça e Cidadania, que é responsável pelo planejamento e execução das políticas agrária e fundiária do Estado. A titulação dos territórios quilombolas possibilita segurança jurídica para as famílias e um alcance maior de políticas públicas direcionadas a esse grupo social. O título do território quilombola é coletivo, esse é entregue à associação de moradores da comunidade.

${ }^{11}$ Informações retiradas do site da Fundação ITESP.

Disponível em <http://www.itesp.sp.gov.br/br/info/acoes/assitencia quilombos.aspx $>$ acesso em abr.2021.
} 
registro do Sistema Agrícola no Livro dos Saberes em setembro de 2018. Com esse gesto, a luta pelo reconhecimento como patrimônio cultural veio somar-se às lutas pelo direito à terra e contra a construção de barragens no rio Ribeira de Iguape, lutas essas que desde a década de 1980 já vinham aglutinando as diversas comunidades da região (RIBEIRO, 2019, p. 141142).

Para o reconhecimento do SAT quilombola como patrimônio imaterial, o Isa, assessorando as comunidades, elaborou um dossiê (o qual está dividido em volume I e II). Nesse dossiê, foram realizadas as referências ao SAT (Sistema Agrícola Tradicional) e ao SAI (Sistema Agrícola Itinerante). O primeiro, SAT, possui aspectos mais abrangentes, pois inclui os bens associados, como a cultura material, contextos de consumo e arranjos produtivos. Enquanto o segundo, SAI, salienta aspectos técnicos e ecológicos do cultivo no modelo da roça de coivara itinerante.

O pedido para o reconhecimento das roças tradicionais quilombolas como patrimônio cultural fez parte de uma política de expansão da patrimonialização em territórios não antes incorporados nos trabalhos de atuação do Iphan. A mobilização desse grupo social se valeu do privilégio de "expansão dessas políticas em São Paulo com diversas ações que resultaram no tombamento de Iguape e dos bens de Imigração Japonesa e da proposta de chancela da passagem cultural”, entre outros (PEREIRA, 2020, p.183).

O bem cultural registrado consiste nos saberes e modos de fazer relacionados à prática das roças tradicionais realizada nos territórios quilombolas do Vale do Ribeira, correspondendo ao:

[...] cultivo nas roças de coivara itinerantes, a diversidade de plantas manejadas, o preparo dos alimentos, a cultura material associada, os arranjos produtivos locais, as redes de comercialização e os contextos de transmissão de conhecimento e de consumo alimentar que envolvem expressões de música e dança. É entendido, portanto, como uma expressão cultural que possui múltiplas dimensões. O uso do termo "sistema" busca enfatizar as interrelações entre os aspectos técnicos, ecológicos, simbólicos e sociais, em acordo com as definições apresentadas por pesquisadores, grupos de trabalhos e instituições que abordam o tema (ANDRADE e KISHIMOTO, 2017, p.6).

O ponto de partida para o registro foi a distinta maneira de conceber a vida e sua relação com a natureza; assim, o manejo e o cultivo tradicional dos alimentos foram condições para a permanência das comunidades quilombolas em vales e montanhas da Mata Atlântica, em lugares mais remotos da região do Vale do Ribeira. Por centenas de anos, os quilombolas, com suas interações no espaço, criaram formas próprias de organização social, usos, tradições, costumes, valores e representações sobre o território tradicional, e esses 
aspectos deixaram marcas na paisagem da Mata Atlântica (ANDRADE e KISHIMOTO, 2017).

As populações tradicionais que vivem na região em torno do rio Ribeira de Iguape com seus saberes, seus conhecimentos espaciais e de manejo, souberam respeitar e defender a manutenção do meio ambiente, o que permitiu que a paisagem da Mata Atlântica que integra esta região fosse conservada, ou seja, a existência dessas populações não constitui ameaças à natureza como muitos ambientalistas tradicionais defendem; pelo contrário, boa parte da floresta preservada coincide com as áreas ocupadas por estas comunidades. Assim, compreendemos que:

Nestas áreas ocupadas por populações tradicionais e suas respectivas atividades de subsistência, as quais são suporte físico para o desenvolvimento de diversas manifestações culturais que representam relevante patrimônio imaterial, devem ser garantidas as condições necessárias ao seu exercício, transformação e continuidade no tempo, e de acordo com os seus padrões culturais e suas tradições. Entende-se aqui por tradição o processo histórico pelo qual os elementos da cultura são continuamente reinterpretados e incorporados ao modo de vida, e não como algo que é imutável (NASCIMENTO; SCIFONI, 2010, p.45).

Embora haja modificações no sistema agrícola tradicional, ao longo do tempo, ele é resultante dessas transformações históricas advindas das experiências adquiridas pelas comunidades negras desde o período colonial, e, contudo, continua como o principal meio de garantia do modo de vida ${ }^{12}$ das muitas famílias quilombolas (ANDRADE e KISHIMOTO, 2017).

O modo de vida quilombola está intrinsecamente ligado ao território ancestral. Esse representa um conjunto de relações que se destaca a identidade de grupo, a vida comunitária, o lugar da reprodução da vida, o etnoconhecimento que se possui da natureza e o espaço que se realiza "na autonomia, na reciprocidade, na hierarquia familiar e as relações complementares de gêneros" (DE BIASE, 2016, p. 17). Somando-se a esses elementos, a religiosidade, por meio da devoção quilombola que irá integrar toda uma relação da territorialidade ao grupo. Acrecentando a existência de uma centralidade do sistema agrícola baseado na roça tradicional para a identidade quilombola (ADAMS, 2017).

\footnotetext{
${ }^{12}$ Compreendemos o modo de vida como um conjunto de relações familiares, de parentesco, de compadrio e de vizinhança, formas de organização da produção imediata, condições materiais de vida e de trabalho, relações políticas e religiosas. Ele está vinculado às relações sociais não capitalistas de produção, pois "tais relações se apoiam num sistema de valores que lhes dá sentido" (MARQUES, 1994, p. 04).
} 
Durante os anos 1980, quando se passou a reconhecer os direitos territoriais quilombolas, ocorre a intensificação do processo com a criação das primeiras associações de moradores em territórios remanescentes de quilombos. A territorialização dos quilombos do Vale do Ribeira passou e ainda passa por diversos desafios, entre eles, estão os atuais conflitos nas chamadas terras de negros face às dificuldades engendradas na sua historicidade, na luta pela terra e resistência em permanecer no território ancestral, locus de sua cultura, particularmente, a partir do reconhecimento destes sujeitos sociais enquanto remanescentes de quilombos (SOUSA, 2015).

No contexto de luta por reconhecimento, as comunidades quilombolas iniciam um processo de mobilização política em diversos níveis e criam uma rede de apoio com instituições, entidades e ONGs (Fundação Instituto de Terra de São Paulo - ITESP; Mitra Diocesiana de Registro e a de Eldorado; Movimento dos Ameaçados por Barragens - MOAB; Equipe de Articulação e Assessoria às Comunidades Negras - EAACONE e Instituto Socioambiental - ISA) com intuito de garantir a proteção dos seus territórios:

Em 1989, com a iminência da construção da usina hidrelétrica de Tijuco Alto, no Rio Ribeira, os quilombolas ajudaram a fundar o Movimento dos Ameaçados por Barragem (MOAB). A barragem do Rio Ribeira representava uma ameaça às populações que ocupavam a região, impondo um modelo de desenvolvimento que colocava em risco o modo de vida e a própria permanência destas comunidades em seus territórios. Outros empreendimentos vieram se somar ao conjunto de pressões, como os projetos de mineração, madeira e monocultura extensiva. Paralelamente ao avanço do projeto desenvolvimentista, o Estado de São Paulo criou unidades de conservação em sobreposição aos territórios quilombolas restringindo as roças tradicionais sob o argumento de que as práticas agrícolas utilizadas prejudicam o meio ambiente (ANDRADE e KISHIMOTO, 2017, p.8).

Dada as circunstâncias adversa e conflituosa, as comunidades quilombolas criaram modos de resistência face ao desenvolvimento de empreendimentos capitalistas, de um lado, e às restrições ambientais, com a criação das Unidades de Conservação (UC), por outro. Estes fatos corroboram no entendimento da importância dos seus territórios (que abrigam patrimônio cultural e natural) e que não somente resguardam a memória destes sujeitos sociais, como são garantia da qualidade de vida das futuras gerações.

Reconhecer o sistema agrícola tradicional das comunidades quilombolas como patrimônio cultural brasileiro é de suma importância para visibilidade destes sujeitos sociais, assim como ecoar para a sociedade envolvente, suas vozes, visões e versões de seus etnoconhecimentos acumulados. O registro do SAT considerou dezenove (19) comunidades quilombolas situadas em seis (6) municípios da Região do Vale do Ribeira paulista, que são: 
Morro Seco (Iguape); Mandira (Cananéia); Abobral Margem-Esquerda (Eldorado); Poça (Eldorado e Jacupiranga); Pedro Cubas (Eldorado); Pedro Cubas de Cima (Eldorado); Sapátu (Eldorado); André Lopes (Eldorado); Ivaporunduva (Eldorado); Galvão (Eldorado); São Pedro (Eldorado); Nhunguara (Eldorado e Iporanga); Piririca (Iporanga); Maria Rosa (Iporanga); Pilões (Iporanga); Bombas (Iporanga); Praia Grande (Iporanga); Porto Velho (Iporanga); e Cangume (Itaóca) (ANDRADE e KISHIMOTO, 2017, p.16).

O processo da patrimonialização do modo de fazer a roça tradicional e os diversos elementos relacionados à prática da agricultura de coivara (agricultura itinerante) - que está intrinsecamente ligada à história e a formação do modo de vida das comunidades e do Vale do Ribeira -, amplia a perspectiva sobre a relevância e abrangência desse bem cultural. Assim, alguns debates foram necessários junto às comunidades para a elaboração e solicitação do registro do bem como cultura imaterial:

A partir de então, buscou-se uma designação que pudesse traduzir a ideia de um conjunto de elementos socioculturais no qual o modo de fazer roça seria seu eixo estruturante. As concepções de "sistema", "tradicional" e "quilombola" foram sendo amadurecidas em diversos momentos do processo de reflexão sobre o bem cultural. (ANDRADE e KISHIMOTO, 2017, p. 8).

No SAT quilombola, o cultivo e o manejo das espécies de plantas realizados no espaço destinado às roças se configuram como eixo central. Temos que a "roça de coivara"13, como denominada pelos quilombolas, se caracteriza pela diversidade de espécies de plantas e variedades manejadas, sendo a maioria delas para fins alimentares das famílias, baseada no rodízio das áreas de plantio e pelo uso do fogo como técnica de abertura das clareiras (acero $)^{14}$ e nutrição do solo.

Cabe aqui destacar que, o direito da realização das roças tradicionais quilombolas é previsto em lei ${ }^{15}$. A cada manejo da mata por uma família quilombola, para a realização de

13 "A legislação ambiental brasileira, com muito atraso, passou a reconhecer o direito das comunidades tradicionais ao etnodesenvolvimento e à prática de atividades agrícolas. A Lei $\mathrm{n}^{\circ}$ 11.428/2006, conhecida como Lei da Mata Atlântica, trata de forma especial as populações tradicionais, permitindo corte, supressão e exploração de vegetação em algumas situações e a exploração eventual de espécies de flora nativa para consumo próprio, bem como simplificando procedimentos para concessão de autorizações ambientais. A Lei $\mathrm{n}^{\circ}$ 12.651/2012 (Código Florestal) também regulamenta de modo diferenciado a situação das comunidades tradicionais, classificando atividades de exploração agroflorestal sustentável como de interesse social e autorizando, de forma expressa, no artigo 38, o uso de fogo na agricultura de subsistência exercida por populações tradicionais" (HAYAMA, 2017, p.109).

${ }^{14} \mathrm{O}$ acero é uma faixa limpa que demarca os limites da área e impede que o fogo se alastre na mata (ANDRADE e KISHIMOTO, 2017, p.26).

15 O inciso I do artigo $3^{\circ}$ do Decreto 6040/2007, que estabelece a Política Nacional de Desenvolvimento Sustentável de Povos e Comunidades Tradicionais, traz a seguinte definição: "I - Povos e Comunidades Tradicionais: grupos culturalmente diferenciados e que se reconhecem como tais, que possuem formas próprias 
uma nova roça, deverá ser solicitado um requerimento de licenciamento prévio. No entanto, para as comunidades, esse procedimento é bastante burocrático e moroso e, em algumas situações, a autorização chegava após o período de plantio. As roças tradicionais fazem parte da luta das comunidades quilombolas na proteção aos seus territórios e à sua cultura. É importante perceber que a comunidade quilombola "não é compreendida por seus integrantes apenas como uma 'união de pessoas', mas como uma unidade que integra estas pessoas aos seus espaços de produção e reprodução da vida" (DE BIASE, 2016, p. 125-126).

A valorização do SAT quilombola, agora patrimônio cultural brasileiro, possibilitará proteger esse bem imaterial dos riscos e ameaças que podem ser de ordem externa e interna às comunidades, além do entendimento de que ele é parte do processo de transformação histórica da sociedade e do modo de produzir no campo. Para a realização da salvaguarda dos bens imateriais, é primordial destacar as narrativas dos sujeitos sociais detentores/produtores dos saberes e manter os contextos socioculturais nos quais os bens estão inseridos.

A garantia de continuidade do SAT quilombola só será possível se houver a defesa dos seus territórios (locais da reprodução física da vida e cultural das comunidades quilombolas), já que a insegurança territorial imposta pelos processos inconclusos de regularização fundiária é uma das principais ameaças a este bem cultural. A maioria das comunidades quilombolas que estão situadas no Vale do Ribeira não possui a titulação de seus territórios tradicionais, e muitos nem se quer foram reconhecidos. Além disso, há ameaças recorrentes de ocupações de "gente de fora" das comunidades, pessoas que não respeitam e nem participam da mesma vida comunitária, e que geralmente introduzem monoculturas cultivadas com agrotóxicos no campo. Garantir que os quilombolas tenham acesso à terra a fim de respeitar-se o seu modo de vida é condição sine qua non para a reprodução da vida, a proteção da agrobiodiversidade e a segurança alimentar desses sujeitos sociais. Outros eixos importantes e que se destacam na garantia protetiva dos quilombolas refletem-se na permissão da comercialização dos produtos e formação de renda, na educação e transmissão de conhecimentos tradicionais e nas implementações da legislação e políticas públicas (ANDRADE e KISHIMOTO, 2017).

No que diz respeito ao registro do SAT quilombola pelo IPHAN, esse permite lançar luz sobre a iniciativa de proteção a bens culturais, além de dar visibilidade às comunidades. Também é possível, a partir dessa decisão, fomentar a consciência desses sujeitos no mundo e

de organização social, que ocupam e usam territórios e recursos naturais como condição para sua reprodução cultural, social, religiosa, ancestral e econômica, utilizando conhecimentos, inovações e práticas gerados e transmitidos pela tradição". 
garantir outras políticas públicas para implementar ações e estratégias que visam contribuir na formação política e no protagonismo dos quilombolas.

A atuação e mobilização política dos grupos subalternos em garantir seus direitos poderiam valer-se da utilização de outros instrumentos de patrimônio, como por exemplo, o patrimônio que se aplica sobre o espaço e não somente sobre os saberes, com o registro de tombamento. Neste quesito, como apresenta Castro (2005), o parágrafo $5^{\circ}$ do artigo 216 da Constituição Federal de 1988 destaca o tombamento de quilombos, ação nunca efetivada pelo Iphan.

Atualmente, há alguns desdobramentos importantes para as comunidades quilombolas com a conquista do registro do SAT como patrimônio da cultura imaterial, dentre eles, o lançamento do livro "Roça é Vida"16, escrito e ilustrado por quilombolas, aquilombadas, profissionais das ciências humanas e exatas, engajados com o movimento social quilombola e educadores sociais. Trata-se de um produto do reconhecimento das roças tradicionais quilombolas como patrimônio cultural brasileiro, apto a permitir o entendimento da sociedade sobre os valores e a importância deste bem cultural.

\section{CONSIDERAÇÕES FINAIS}

Ressaltamos aqui a importância e a complexidade do estudo sobre o campo do patrimônio cultural, particularmente, do imaterial. Compreendendo que o registro e o reconhecimento desse patrimônio objetivam a construção de ações afirmativas importantes para os grupos subalternos solicitantes como forma de salvaguardar o bem cultural. O percurso para a implementação das políticas de reconhecimento de patrimônio imaterial, como salientamos, passou por avanços e retrocessos a partir das décadas de 1970 e 1980.

A complexidade de trabalhar com a cultura e, em consequência, com o patrimônio cultural deve ser destacada, pois se trata de um campo eminentemente político. Por isso, ter postura crítica é condição para atuar nesse campo. No momento atual de crise econômica e, por que não dizer, de crise política que o país atravessa, as políticas públicas voltadas às populações subalternas, dentre essas, a população negra, são menosprezadas, sucateadas e desmontadas. Romper com a invisibilidade social e chamar atenção à luta pelos direitos desses grupos sociais, dando garantia de políticas públicas de proteção do patrimônio imaterial, são medidas tidas como fundamentais para diminuir o risco de perda de sua cultura.

\footnotetext{
${ }^{16}$ O livro "Roça é Vida" foi publicado em 2020 pelo IPHAN, uma realização do Grupo de Trabalho da Roça em parceria com União Europeia, ISA, IPHAN e Ministério do Turismo.
} 
O registro do Sistema Agrícola Tradicional quilombola do Vale do Ribeira tem força de impulsionar outras lutas dedicadas à proteção de bens culturais das populações tradicionais brasileiras.

Obter o reconhecimento do patrimônio cultural imaterial não implica desconhecer as limitações da política do imaterial para o objetivo fundante dos quilombolas, que é o direito e a defesa de seus territórios ancestrais.

Em tal perspectiva, o registro do SAT quilombola mostrou-se um importante meio para a proteção do apontado bem cultural, além de dar maior visibilidade às populações quilombolas do Vale do Ribeira. Reconhecer as roças quilombolas como patrimônio cultural brasileiro potencializa o arcabouço cultural dessa população tradicional e dá condições para engendrar, junto aos órgãos responsáveis, novas lutas por políticas públicas que estejam em consonância com as demandas mais urgentes das comunidades tradicionais.

Contudo, espera-se que, a partir do registro do SAT quilombola e da publicação do livro "Roça é Vida", a sociedade brasileira conheça mais sobre os valores e a importância desse e de outros bens que configuram a cultura quilombola do Vale do Ribeira, além de servir como referência para as demais comunidades tradicionais e outros grupos subalternos existentes em todo o país.

\section{REFERÊNCIAS}

ADAMS, Cristina. Apresentação. Dossiê (Sistema Agrícola Tradicional Quilombola do Vale do Ribeira-SP. ADAMS, Cristina [et al.]. - vol. II, São Paulo:Instituto Socioambiental, 2017. Disponível em:<https://acervo.socioambiental.org/acervo/documentos/dossie-sistemaagricola-tradicional-quilombola-do-vale-do-ribeira-sp-vol-2>. Acesso em: 22 set. 2020.

ARRUTI, José Maurício. Propriedade ou território? Tempo e Presença, v.21, no 307, p.1014, set.-out., 1999.

ANDRADE, Anna Maria; TATTO, Nilto (ed.). Inventário cultural de quilombos do Vale do Ribeira. São Paulo: Instituto Socioambiental, 2013. Disponível em: $<$ https://acervo.socioambiental.org/sites/default/files/publications/pdf-publicacaofinal_inventario.pdf $>$. Acesso em: 15 jan. 2014.

ANDRADE, Anna Maria de Castro; KISHIMOTO, Alexandre (org.). Dossiê Sistema Agrícola Tradicional Quilombola do Vale do Ribeira. - vol. I, São Paulo: Instituto Socioambiental, $2017 . \quad$ Disponível em: $<$ https://acervo.socioambiental.org/acervo/documentos/dossie-sistema-agricola-tradicionalquilombola-do-vale-do-ribeira-sp-vol-1>. Acesso em: 12 set. 2020. 
BENJAMIN, Walter. O Narrador: considerações sobre a obra de Nikolai Leskov. In: Magia, Técnica e política: Ensaios sobre literatura e história da cultura. Walter Benjamin; tradução Sérgio Paulo Rouanet; prefácio Jeanne Marie Gagnebin - $8^{\mathrm{a}}$ Ed. revista - São Paulo: Brasiliense, 2012 - (Obras Escolhidas, vol. 1).

BRASIL, [Constituição (1988)]. Constituição da República Federativa do Brasil: texto constitucional promulgado em 5 de outubro de 1988, com as alterações determinadas pelas Emendas Constitucionais de Revisão nos 1 a 6/94, pelas Emendas Constitucionais nos 1/92 a 91/2016 e pelo Decreto Legislativo no 186/2008. - Brasília: Senado Federal, Coordenação de Edições Técnicas, 2016. 496 p.

CARNEIRO DA CUNHA, Manuela. Introdução. Manuela Carneiro da Cunha (Org.) In: Revista do Patrimônio Histórico e Artístico Nacional - Patrimônio imaterial e biodiversidade. no 32 - Brasília, 2005. p. 15 - 27. Disponível em: <http://portal.iphan.gov.br/uploads/publicacao/rev_pat_n32.pdf >. Acesso em: 25 out. 2020.

CASTRO, Adler Fonseca Homero. Quilombos: comunidades e patrimônio. Revista Eletrônica do IPHAN: Dossiê Brasil afrodescendente. Rio de Janeiro, n ${ }^{\circ} 1$ set./out.de 2005. Disponível em: <http://www.labjor.unicamp.br/patrimonio/materia.php?id=55>. Acesso em 18 fev. 2021.

CHAUÍ, Marilena. Conformismo e resistência: aspectos da cultura popular no Brasil. In: Conformismo e Resistência - Escritos de Marilena Chauí; vol.4- Homero Santiago ORG. Editora Fundação Abramo - Belo Horizonte, AUTÊNTICA, 2014.

DE BIASE, Laura. Agroecologia quilombola ou quilombo agroecológico? Dilemas agroflorestais e territorialização no Vale do Ribeira/SP. Tese (Doutorado em Geografia Humana) - FFLCH/USP. São Paulo, 2016.

HAYAMA, Andrew Toshio. Defesa do Sistema Agrícola quilombola do Vale do Ribeira como patrimônio cultural imaterial brasileiro. In.: ADAMS, Cristina [et al]. Dossiê (Sistema Agrícola Tradicional Quilombola do Vale do Ribeira-SP. ADAMS, Cristina [et al.]. - vol. II, São Paulo: Instituto 2017. $<$ https://acervo.socioambiental.org/acervo/documentos/dossie-sistema-agricola-tradicionalquilombola-do-vale-do-ribeira-sp-vol-2>. Acesso em: 22 set. 2020.

LUIZ, Viviane Marinho [et. al.]; ROÇA é VIDA. LUIZ, Viviane Marinho; SILVA, Laudessandro Marinho da; AMÉRICO, Márcia Cristina; DIAS, Luis Marcos de França (Org.) - Grupo de Trabalho da Roça. Ilustradores Amanda Nainá dos Santos (NAINÁ) e Vanderlei Ribeiro (DECO). São Paulo: IPHAN, 2020. 27p. Disponível em: <https://acervo.socioambiental.org/sites/default/files/documents/prov61.pdf>. Acesso em: 10 jan. 2021.

MARQUES, Marta Inez Medeiros. O modo de vida camponês sertanejo e sua territorialidade no tempo das grandes fazendas e nos dias de hoje em Ribeira-PB. Dissertação de mestrado do Programa de Pós-Graduação em Geografia Humana do Departamento de Geografia da Faculdade de Filosofia, Letras e Ciências Humanas da Universidade de São Paulo, 1994, 158 p. 
MENESES, Ulpiano Toledo Bezerra de. O campo do patrimônio cultural: uma revisão de premissas. Instituto do Patrimônio Histórico e Artístico Nacional (Iphan). I Fórum Nacional do Patrimônio Cultural: Sistema Nacional de Patrimônio Cultural: desafios, estratégias e experiências para uma nova gestão, Ouro Preto/MG, 2009 / Instituto do Patrimônio Histórico e Artístico Nacional; coordenação, Weber Sutti. -- Brasília, DF: Iphan, 2012, vol. $1, \quad$ p. 25-39. Disponível em: <http://portal.iphan.gov.br/uploads/publicacao/Anais2_vol1_ForumPatrimonio_m.pdf>. Acesso em 28 mar. 2020.

NASCIMENTO, Flávia Brito do; SCIFONI, Simone. A paisagem cultural como novo paradigma para a proteção: a experiência do Vale do Ribeira - SP. In.: Revista CPC, São Paulo, no. 10, p. 29-48, maio/out 2010. Disponível em: <https://www.revistas.usp.br/cpc/article/view/15660>. Acesso em: 29 set. 2020.

NORA, Pierre. Entre memória e história. A problemática dos lugares. Tradução Yara Khoury. Revista Projeto História, São Paulo, nº10, 1993. Disponível em: < https://revistas.pucsp.br/index.php/revph/article/view/12101>. Acesso em 21 out. 2020.

PEREIRA, Danilo Celso. Patrimônio Natural: atualizando o debate sobre identificação e reconhecimento no âmbito do Iphan. In.: Rev. CPC, v.13, n.25, p.34-59, jan./set. 2018. Disponível em: <https://www.revistas.usp.br/cpc/article/view/138007>. Acesso em: 30 set. 2020.

A chancela da Paisagem Cultural Brasileira: 10 anos de caminhos e descaminhos de uma política de cultura com compromisso social. In.: Revista Memória em Rede, Pelotas, v.12, n.22, p.173-197, jan./jun.2020 - ISSN - 2177-4129. Disponível em: https://periodicos.ufpel.edu.br/ojs2/index.php/Memoria/article/view/16018/11051. Acesso em: 20 out. 2020

RIBEIRO, David William Aparecido. Patrimônio socioambiental e narrativas da resistência quilombola. Revista Iberoamericana de Turismo-RITUR, Penedo, Vol. 9, Número Especial, Mar. 2019, p. 138-153. Disponível em:< http://www.seer.ufal.br/index.php/ritur >. Acesso em: jan. 2020.

SMITH, Laurajane. El "espejo patrimonial” ¿ Ilusión narcisista o reflexiones múltiples? Antipoda Revista de Antropologia y Arqueología, nº. 12, 262 p., Bogotá, Enero-Junio 2011, p. 39-63.

SOUSA, Denise Martins de. Da luta pela terra à territorialização quilombola: $O$ caso da comunidade Porto Velho, Iporanga/SP. Dissertação de mestrado do Programa de PósGraduação em Geografia Humana do Departamento de Geografia da Faculdade de Filosofia, Letras e Ciências Humanas da Universidade de São Paulo, 2015, 258p.

Artigo recebido em: 19 de março de 2021.

Artigo aceito em: 27 de maio de 2021.

Artigo publicado em: 01 de julho de 2021. 